\title{
Discussion on Fusion Method of Tradition and Modernity in Architecture
}

\section{Design}

\author{
F. X. OUYANG
}

School of civil engineering and architecture, Wuhan polytechnic university, Wuhan, 430023

KEYWORD: cultural tradition in architecture design; modern function in architecture design; fusion method

ABSTRACT: The tradition of architecture design is a complete set of expression symbol formed within a specific region, with the edification of the region's unique culture and after a long time of precipitation

It is in line with people's aesthetic, is a summary of the people's living demands, and also a unique "culture" with regional features. However, with the development of society and economy, people's living demands are also changing, which means blindly following regional architectural tradition cannot meet the requirements of contemporary people. The correct way is to combine with external characteristics of natural environment and resources and new living demand characteristics, design architecture complying with traditional aesthetic requirements, meeting contemporary people's living demands, and fitting in external environment as well, and to advocate energy conservation and environment protection and sustainable development, thus requiring architecture design to have the "function" in accordance with the current era. In fact, the fusion of tradition and modern in architecture design is the fusion of "culture" and "function", and is also the expression of architecture design advancing with the times. This thesis conducted research on the fusion method of tradition and modern in architecture design provided.

\section{INTRODUCTION}

"Region" is the geographic background of culture formation and the birth place of culture. Regional culture is the unique culture integrating with environment and having regional mark in a certain geographical environment, and is continually created by people in daily life and production from different regions. Goethe said, "Architecture is the book of stone", which shows that architecture is an expression of culture. The original architecture is a place created by people for adapting to natural environment changes. Due to the diversity of the world, different regions have different natural environment resources, and naturally, people adjust measures to local conditions and obtain materials from local sources, then come cave architecture, stone architecture, timber architecture, etc. With the development of society and economy, the requirements of people on architecture change from simple living demand to the higher level of expressing their own ideas. In this process, different regional cultures are integrated into architecture by unconsciously influenced, thus forming regional architecture with abundant connotation, distinctive characteristics and different styles through the accumulation of history.

Regionalism is a fundamental attribution of architecture and regional architecture has abundant colors.

With a vast territory, numerous nationalities, variable terrains and diverse climates, development between regions in China is highly uneven. From architectural history, the architecture changes with region is much greater than that with time, so the regionalism of architecture has become an indispensable feature of Chinese architecture, which reflects the essence of Chinese architectural culture. 
The globalization trend makes the Earth become a global village owned by all mankind, shortens the distance of time and space and reduces differences between regions, leading to the risk of regional culture being assimilated and extinct. In architecture, globalization brings the latest architectural technologies and materials and new architectural theories, schools and forms to each country. While at the same time it brings new ideas to regional architecture culture of the world, it also brings a strong impact. Global cultural convergence, caused by globalization, reflects in architecture is that the regional culture of architecture is gradually overwhelmed by global culture, and the "national character" of architecture is replaced by "international". As the soul of city and architecture, regional culture is gradually at the risk of fading and disappearing. Under the situation of globalization and cultural convergence, how to protect and develop regional architecture culture and how to organically integrate regional architecture culture and architecture's modern functional requirements is particularly important.

\section{REGIONALISM AND MODERNIZATION OF ARCHITECTURE}

\section{Regionalism of Architecture}

Firstly, architecture is the product of a region. It is rooted in a specific environment and constrained by conditions of geography, climate and culture, and after a long time of precipitation, it formed a unique architectural style in the region, namely the regionalism of architecture. For example, Hui style architecture, Suzhou gardens, Tujia stilted building, etc.

\section{Modernization of architecture}

Modernization of architecture is to apply modern science and technology and use advanced building materials to build architecture, which integrates with surrounding environment, advocates energy conservation and is good for living. Such as the latest headquarter of Google, World Expo China Pavilion and Saudi Pavilion, etc.

\section{Relationship between regionalism and modernization of architecture}

The regionalism and modernization of architecture is to see architecture design from different perspectives. The regionalism of architecture focuses on adaptation to the environment, lacking of reasonably use of the environment and sustainable development; the modernization of architecture pays more attention to practicality of architecture, giving priority to being good for living but ignoring that architecture is definitely a behavior reflecting the thought of a particular environment and a certain cultural background. The two have different emphases, the former focuses on considering from architecture exterior (namely the relationship between architecture and external environment), while the latter lays emphasis on starting with architecture interior (namely, architecture is to make people live comfortably).

The regionalism and modernization of architecture promote and restrict each other. The organic integration of regionalism and modernization enables us to design more reasonable and livable architecture, while how to integrate and reflect regionalism and modernization in architecture design is very important and worth considering.

\section{WAYS ON FUSION OF TRADITION AND MODERNITY IN ARCHITECTURE DESIGN}

\section{Tradition is the foundation of modern development}

Tradition and modernity are in ordered relation of transition from time and space. Tradition represents the past, while the modern is developed from tradition, which means tradition is the premise and foundation of modern development, and modern development will be interrupted without tradition. Tradition is the hereditary part in development process. It not only belongs to the 
past, but still plays a role in real life today. The speed and height of development are always influenced by tradition in different degrees, so to fully discover and utilize value and power advantages of tradition is the deciding factor in quickly and orderly modern development. The traditional architecture design styles are formed after a long time, therefore, the modernity of each architecture design should be based on traditional architecture style of its own region, and should not appear out of nowhere, otherwise, it will be obtrusive and antipathetic.

\section{Modern development must break through tradition}

Tradition is not immutable but a relatively stable variable. In history, tradition experienced the test of time and stayed, getting understanding and recognition from most people and forming a conventional idea. Complying with social development trend is the reason why tradition stands still. Therefore, in a way, tradition has a certain advanced nature. However, the premise of the emergence and development of new things is to break loose from tradition, that is to say, it must treat tradition properly, neither completely complying with tradition or being afraid of changing tradition, nor completely ignoring or denying the meaning of tradition. In short, development in modern should be creative and based on inheriting the tradition.

\section{MODERNIZATION OF REGIONAL ARCHITECTURE}

The generation of traditional regional architectures was based on traditional culture, whose functions were adapted to people's life and culture at that time on the basis of technology and economic conditions of the time, but they were lack of considerations on the aspects of quakeproof and fireproofing. In traditional societies, regional architectures were featured by single function, poor ventilation and sunshine conditions. The development of human society and economy and the improved people's living standard made people have higher and more complicated requirements on functions of architectures. Traditional regional architectures can't meet the demands, so we need to upgrade traditional architectures or in current design of architectures, give full consideration to the positive aspects of traditional regional architectures to design architectures that are more reasonable and can better meet the needs of contemporary society.

In meeting functional requirements, sometimes traditional regional architecture can't reach these, so we need to conduct organic renewal on traditional architecture to make it possess merits of traditional regional features, at the same time help to solve remained issues. Architects should combine the energy conservation design in traditional regional folk houses with modern technology to conduct necessary improvement and renewal, giving new vitality to architectures with traditional regional characteristics.

On one hand, architects should integrate into the development trend of global culture, learning experience of excellent architectural culture from various countries and regions. On the other hand, architects should commit to protect China's outstanding architectural cultural heritage, digging local cultural characteristics.

Creation should be conducted in combination with function, technology and material of modern architecture and with plane layout, spatial layout and construction mode of traditional architecture. After extracting and purifying, the creation should be applied in modern architectural creation. Traditional architecture should express more modern elements under unified overall style.

\section{Research on adaptability of inside and outside architecture}

Traditional regional architecture is an architectural form built by incorporating local natural environment, humanity factor, culture and history and national features that meets local material and cultural needs and is full of local people's wisdom and diligence. But with the development of economy and understanding of foreign culture, people's material and cultural needs have increased 
gradually. Traditional regional architecture exposed many defects and shortcomings, such as bad shock resistance, poor sanitation condition, inadequate ventilation and lighting, etc. In order to maintain regional architecture's vitality and develop style and feature of local architecture, architects must use modern science and technology to conduct reform and innovation on traditional regional architecture.

\section{Promote contemporary practicability of architecture}

With the rapid development of society and economy and increasing growth of population, available spaces and resources are reduced relatively. Regional architectures have great deficiency on aspects of energy saving and environment protection, efficient utilization of spaces, etc. In order to improve practicability of architectures and achieve sustainable development, architects must utilize modern architectural technology and material to arrange architectural space scientifically and upgrade using functions of regional architecture. For example, at present China advocate high-rise housing to save land resources; Wuhan Garden Expo took the principle of using local materials and repeated usage when choosing building materials.

\section{Integrate advantages of architectures from other regions}

Architectures from different regions have different advantages. In the process of global integration, adaptability and practicability of our architecture can be further enhanced through learning advantages of architectural design of other regions.

\section{LOCALIZATION OF MODERN ARCHITECTURE}

Regional architecture is the manifestation of regional culture in the physical environment and space configuration. From external shaping to interior decoration of buildings all reflect a nation's cultural spirit, value, religious belief, artistic standard, social custom, lifestyle, social codes of conduct and other levels of social life. The design and creation of architecture should be regional and historic. Architects gain emotional sense of belonging and identity from aspects of form, volume, space, materials and temperament based on deep analysis of features of regional culture to make architectures become the inheritance and continuity of traditional culture and local features.

In the context of globalization, the renewal of regional architecture contains protection, development and innovation, which requires architects to not only integrate into the global trend of cultural development, actively learning outstanding architectural culture of various countries and regions, but also protect China's excellent heritage of architectural culture, digging features of local culture. Architects should immerse traditional essence into modern architecture design, import content of modern life, reflect the concern of people, meet people's spiritual needs and create emotional spaces identified by Chinese people, which requires architects to have a broader cultural context and can grasp the development trend of contemporary architecture. Specifically, it contains the following aspects.

\section{Research and create spatial characteristics of China's regional architecture}

Architecture modernization focuses on buildings' practicality, however, architectures must be in specific natural and cultural environments and regional architecture pays attention to this. When designing architectures, architects should combine "aura" of regional architectures with practicality and rationality of modern architectures to create architectures that conform to both local people's aesthetic habits and modern people's life demands. Traditional architectural elements reflect traditional culture and the combination of modern architectural design and traditional cultural elements can create style features of concise beauty, spatial beauty and artistic beauty. In modern architectural design, architectural design that can truly reflect traditional Chinese culture is not a simple imitation and copy, but a recreation of traditional form that uses a figural factor and adopts 
techniques of exaggeration and distortion, then through extraction and application, it can give cultural elements of traditional architecture new vitality and make architectural design have updated era character on traditional basis. The key point for modern architecture to inherit and develop traditional culture is to meet the theme expressed by modern architecture and adapt to its development trend. Architects need to find a realistic pointcut to make modern architecture reflect a strong sense of modern design and national feature, embodying vivid cultural meanings and modern aesthetic characteristics through the traditional form.

For example, Jinmao Tower in Shanghai. Its profile reminds people of pagodas in ancient China. Double-axisymmetric tower form makes people enjoy the full view from any viewing angles of Shanghai. Stair-step shape stretches upwards to the soaring spire with a gradually accelerated rhythm. Jinmao Tower expresses traditional culture with an abstract way and utilizes advanced technology positively but not imitation and stiff repetition of specific forms.

\section{Respect natural and cultural environment of architectures}

When designing architecture, architects can't only focus on architecture's practicability, for architecture exists in a certain region, under a certain cultural background and should be used by local people. The design should be combined with local geographic feature and cultural feature and try to be harmonious with surrounding buildings.

For example, the new site of Suzhou Museum. In general, the new site learned from traditional courtyard-style layout and courtyard space in gardens, adopting traditional architectural materials and architecture symbols creatively but using new expressions. The new site of Suzhou Museum has the wonder of using different approaches to achieve equally satisfactory, aligning well with Suzhou's traditional space layout and city texture.

\section{Update language of regional architecture}

We should treat western architectural cultures with positive and active attitude, but we can never indiscriminately copy them. Different attitudes of western architecture will produce different results. Some external influences can't be chosen, while some can be utilized.

We must inherit connotation and wisdom of traditional architectural culture, but not simply imitate superficial form. The inheritance can be magnificent, but it shouldn't lose its nature; it can be majestic but not be ostentatious; it can have personality, can break unique symmetry, but it must be integrally coordinated, symmetrical and balanced with surrounding natural environment.

\section{CONCLUSION}

\section{Architectural culture is rooted in local culture}

Architecture is an achievement of civilization. When exploring history, modern people can't be inseparable from the study of historic buildings; modern architectures can have vitality only by connecting to history and culture and regarding local culture as an important basis for design and construction.

\section{Modernization of architecture can't blindly pursue westernization}

China's urban construction benefits a lot through learning architectural science and technology from western developed countries. It is totally wrong if people purse westernization on architectural style blindly and equate it with modernization.

\section{Essence and connotation of architecture modernization}

We advocate nationality of architectural culture, but it doesn't mean we only pursue to imitate ancient architecture. It has been found that stiff imitation of ancient buildings has the same damage to city image as blind westernization. Modern architecture only has one goal-architecture modernization. 


\section{REFERENCE}

[1] Li Yi, Zhang Fengjiang, Fission and Choice-Historical Exploration of Relationship Between Traditional Culture and Modernization, Liaoning Education Press, Shenyang Province, 1996, 29 [2] Li Donghong, Tian Fusen, Exploration on Regionalism Principle of Architectural Design: Architectural Engineering Technology and Design, 2014 (15): 108-109

[3] Li Yi, Zhang Fengjiang, Transformation Design of Public Park in Urban Historical Streets: Modern Agricultural Sciences and Technology, 2015(15): 264-265 